\title{
DINAMIKA PERUBAHAN SOSIAL EKONOMI PADA MASYARAKAT KINDANG KABUPATEN BULUKUMBA
}

\author{
Muh. Yusuf ${ }^{1}$, Andi Agustang ${ }^{2}$ \\ ${ }^{1,2}$ Program Studi Pendidikan Ilmu Pengetahuan Sosial Konsentrasi Pendidikan Sosiologi \\ Program Pasca Sarjana Universitas Negeri Makassar \\ Muhammadyusuf20@yahoo.com¹,andiagust63@gmail.com²
}

\begin{abstract}
ABSTRAK
Penelitian ini bertujuan untuk mendeskripsikan bagaimana faktor dan proses perubahan sosial ekonomi serta dampak dari perubahan sosial ekonomi yang terjadi pada Masyarakat Kindang Kabupaten Bulukumba. Jenis penelitian ini menggunakan penelitian kualitatif. Teknik dalam menentukan informan menggunakan teknik snowball sampling, yakni tanpa menentukan kriteria informan, sehingga jumlah informan akan selalu bertambah sesuai dengan kebutuhan informasi pada masyarakat Kindang Kabupaten Bulukumba. Teknik pengumpulan data yang digunakan adalah observasi, wawancara dan dokumentasi. Teknik analisis data yang digunakan peneliti melalui tiga tahapan kerja yaitu: reduksi data, penyajian data, dan penarikan kesimpulan. Pengabsahan data yang digunakan yaitu triangulasi. Hasil penelitian ini menunjukkan bahwa (1) faktor yang menjadi determinan perubahan sosial ekonomi masyarakat kindang adalah hasil tani dari produksi cengkeh yang merupakan komuditi familiar dengan nilai ekonomis yang sangat tinggi saat ini dengan tingkat produktifitas tinggi di kabupaten Bulukumba. (2) Proses perubahan sosial ekonomi pada masyarakat kindang terjadi diantara keadaan dan waktu yang berbeda, dimana masyarakat kindang mengalami krisis ekonomi pada masa orde baru, terbentuknya BPPC (Badan Penyanggah Penanggulangan Cengkeh) yang mengatur dan membeli cengkeh dengn harga yang tidak sewajarnya, kemudian terjadi perubahan secara signifikan pada masa reformasi, dengan adanya keterbukaan dan kebebasan masa reformasi hingga harga cengkeh mulai pulih dan meningkat sehingga dapat mensejahterakan msayarakat kindang. (3) Dampak perubahan sosial ekonomi yang terjadi pada masyarakat kindang kabupaten bulukumba. yaitu meningkatnya sistem perekonomian masyarakat Kindang menajdi masyarakat sejahtera dan stratifikasi sosial yang semakin tinggi, serta semakin tumbuhnya kesadaran masyarakat dalam bidang pendidikan, poitik dan kebudayaan. Kebudayaan dalam hal ini meliputi pola hidup dan pergaulan serta gaya hidup moderen sehingga mengikis budaya- budaya lokal seperti gotong- royong sudah mulai berkurang.
\end{abstract}

Kata kunci: Perubahan sosial ekonomi.

\section{ABSTRACT}

This study aims to describe how the factors and processes of socio-economic change and the impact of socio-economic changes that occur in the Kindang Society of Bulukumba Regency. This type of research uses qualitative research. The technique in determining informants uses snowball sampling techniques, that is, without determining the criteria for informants, so the number of informants will always increase according to the information needs of the Kindang community in Bulukumba Regency. Data collection techniques used were observation, interviews and documentation. Data analysis techniques used by researchers through three stages of work, namely: data reduction, data presentation, and drawing conclusions. Validation of the data used is triangulation. The results of this study indicate that (1) the factors that determine the socio-economic changes of the kindang community are farm produce from clove production which is a familiar commodity with a very high economic value at this time with a high level of productivity in Bulukumba district. (2) The process of socio-economic change in the kindang community occurs between different circumstances and times, where the kindang community experiences an economic crisis in the new order, the formation of the BPPC (Clove Management Agency) which regulates and buys cloves at unreasonable prices, then occurs significant changes during the reform period, with the openness and freedom of the reform period until the price of cloves began to recover and freedom of the reformation period until the price of cloves began to recover and increase so that the welfare of the kindang community could prosper. (3) The impact of socio-economic changes that occur in the kindang community of Bulukumba district. namely improving the economic system of the Kindang community to become a prosperous society and higher social stratification, as well as growing public awareness in the fields of education, politics and 
culture. Culture in this case encompasses lifestyles and relationships and modern lifestyles so that eroding local cultures such as mutual cooperation have begun to diminish.

Keywords: Socio-economic change.

\section{PENDAHULUAN}

Indonesia merupakan salah satu Negara tropis karena diapit dua samudera, yakni samudera Pasifik dan samudera Hindia, sehingga Indonesia banyak menerima curah hujan. Intensitas hujan yang tinggi dan kondisi geografis wilayah yang bergunung merupakan dua faktor yang mendukung kesuburan tanah di Indonesia. Kesuburan tanah di Indonesia hampir merata di seluruh wilayah tidak terkecuali di Sulawesi Selatan. Di bagian selatan sulawesi selatan terdapat jajaran pegunungan Lompo Battang yang meliputi wilayah Kabupaten Gowa, Takalar, Jeneponto, Bantaeng, Sinjai dan Bulukumba (Rohani, 2016).

Secara sosiologis, perbedaan bentang alam akan memberikan pengaruh langsung dalam dinamika sosial antara masyarakat yang satu dengan yang lain. Kabupaten Bulukumba memiliki beberapa kecamatan yang tergolong subur karena terletak di kaki selatan pegunungan Lompo battang. Salah satu diantaranya yakni Kecamatan Kindang. Wilayah Kecamatan Kindang merupakan suatu daerah yang berada di lereng pegunungan. Kondisi ini mempengaruhi aktivitas sosial dan ekonomi masyarakat pada wilayah ini. Ekonomi merupakan suatu hal mendasar dalam kehidupan masyarakat. Dengan adanya ekonomi kehidupan masyarakat akan terjamin, dan dapat memenuhi kebutuhan dasar berupa sandang, pangan, dan papan. Oleh karena itu, ekonomi menjadi hal yang penting dalam perubahan sosial masyarakat (Samud, 2018).

Kindang merupakan daerah yang berada pada wilayah pegunungan dengan sumber penghasilan utama masyarakat yang berasal dari komoditas cengkeh. Kebutuhan pasar serta nilai ekonomis yang tinggi menjadikan komoditas cengkeh sebagai sumber penghasilan utama masyarakat Kindang. Dengan tanaman cengkeh idealnya masyarakat memiliki tingkat perekonomian yang cukup, serta mampu berada pada taraf kehidupan yang lebih baik, khususnya dalam memenuhi kebutuhan sehari-hari. Di samping itu stratifikasi sosial masyarakat Kindang seharusnya semakin meningkat dengan hasil pertanian dan harga jual cengkeh yang baik. Namun kejayaan petani cengkeh itu tak lama. Pada tahun 1980 kondisi sosial ekonomi masyarakat kindang sangat terpuruk dengan harga jual komoditas cengkeh yang rendah. Umumnya hal tersebut diakibatkan oleh pemerintah orde baru yang memainkan monopoli harga pada komoditas cengkeh. Berdasarkan keputusan Presiden pada tahun 1992, dibentuklah Badan Penyangga dan Pemasaran Cengkeh (BPPC) yang dipimpin langsung oleh Tommy. Dalam (Gilarso, 2004), tercatat Tommy masih berusia 28 tahun kala menjadi ketua konsorsium cengkeh. Sebagai pihak satu- satunya yang bisa membeli cengkeh, maka BPPC pun bebas memainkan harga.

Namun Kondisi aktual masyarakat kindang saat ini terjadi kebangkitan dalam bidang perekonomian, khususnya dalam bidang pertanian dengan tanaman cengkeh sebagai komoditas utama. Beberapa informasi yang diperoleh dalam observasi awal menunjukkan realitas sosial baru pada masyarakat Kindang yang jauh berbeda dengan era sebelum reformasi. 


\section{METODE PENELITIAN}

Metode penelitian yang digunakan dalam penelitian ini adalah metode penelitian deskriptif analitik dengan menggunakan pendekatan kualitatif. Penggunaan pendekatan ini disesuaikan dengan tujuan pokok penelitian, yaitu mendeskripsikan dan menganalisis bagaimana dinamika proses perubahan sosial ekonomi Masyarakat Kindang. Desain penelitian analitik adalah suatu desain penelitian yang dirancang untuk mendeskripsikan secara mendetail tentang bagaimana sejumlah individu mengalami suatu fenomena yang spesifik. Dalam mendeskripsikan suatu fenomena secara mendetail, biasanya dilakukan dengan mengumpulkan data dari individu-individu yang pernah mengalami fenomena. Besarnya kelompok individu yang diteliti bisa bervariasi (Creswell, 2009), (Creswell \& Creswell, 2017).

Penelitian yang baik akan menghasilkan paradigma yang baru dalam pengembangan ilmu pengetahuan, dimana hasil pemikiran paradigma selalu tidak mencukupi dan terbuka untuk perubahan selanjutnya. Dengan kata lain hasil pemikiran melalui perubahan paradigma akan selalu bersifat relative, hal ini bergantung pada data dan fakta yang diperoleh dari dunia nyata yang kemudian dianalisis menurut kaidahkaidah ilmiah (Agustang, 2011b). Teknik dalam menentukan informan menggunakan teknik snowball sampling, yakni tanpa menentukan kriteria informan, sehingga jumlah informan akan selalu bertambah sesuai dengan kebutuhan informasi akan diperoleh pada masyarakat Kindang Kabupaten Bulukumba. Teknik pengumpulan data yang digunakan adalah observasi, wawancara dan dokumentasi. Teknik analisis data yang digunakan peneliti melalui tiga tahapan kerja yaitu: reduksi data, penyajian data, dan penarikan kesimpulan (Miles et al., 2014). Pengabsahan data yang digunakan yaitu triangulasi.

\section{HASIL PENELITIAN DAN PEMBAHASAN}

1. Faktor determinan terjadinya perubahan sosial ekonomi pada masyarakat Kindang Kabupaten Bulukumba.

Pada pembahasan ini akan dibahas mengenai faktor determinan terjadinya perubahan sosial ekonomi pada masyarakat Kindang Kabupaten Bulukumba. Berdasarkan penelitian yang telah dilakukan, ditemukan dua faktor trjadinya perubahan sosial pada masyarakat Kindang Kabupaten Bulukumba yakni, faktor eksternal dan faktor internal.

(1). Faktor eksternal yakni: pertama, adanya pengaruh budaya luar, jadi dari hasil observasi dan penelitian yang dilakukan oleh peneliti menunjukkan bahwa perubahan yang terjadi pada masyarakat Kindang Kabupaten Bulukumba itu karena mengikuti perkembangan yang terjadi pada daerah lain dan berusaha mengejar ketertinggalan dari daerah- daerah tersebut, sehingga memotivasi dan menumbuhkan kembali semngat kerja masyarakat yang dimana sebelumnya telah terbentuk karena didikan alam dan orang tuanya untuk bertahan hidup. Kedua, perkembangan teknologi, dari hasil penelitian menjelaskan bahwa seiring dengan berkembangnya zaman yang ditandai dengan lahirnya teknologi yang semakin canggih dan modern seperti handphone (smartphone) yang dapat mengakses berbagai informasi melalui jejaring sosial dan juga dapat melakukan komunikasi lebih luas dan lebih mudah sehingga teknologi tersebut dapat mempengaruhi pola pikir masyarakat Kindang pada umumnya.

(2). Faktor internal yakni: pertama, faktor struktural, dari hasil observasi dan penelitian yang dilakukan oleh peneliti menunjukkan bahwa adanya keterlibatan pemerintah terhadap turunnya harga cengkeh pada masa Orde Baru. Pemerintah 
menerapkan sistem tunggal dengan istilah satu pintu dalam proses jual beli cengkeh. BPPC (Badan Penyangga \& Pemasaran Cengkeh) menjadi pengontrol satu satunya di industri cengkeh. Semua cengkeh dari petani wajib dijual ke Koprasi Unit Desa (KUD). Sebagai pihak satu satunya yang bisa membeli cengkeh, maka BPPC pun bebas memainkan harga. Mereka membeli cengkeh dari petani dengan harga semurah- murahnya, dan menjual ke pabrik rokok semahal-mahalnya. Sehingga menimbulkan pro dan kontra antara masyarakat dengan pemerintah. Hal tersebut menumbuhkan rasa semangat masyarakat untuk memperjuangkan dan mengupayakan agar terjadi perubahan system yang telah diterapkan oleh pemerintah. Hal ini diperkuat oleh Michael Foucault yang dihimpun dalam buku Power/ Knowledge yang menjelaskan mengenai relasi kekuasaan dan pengetahuan sebgai kontrol social (Kebung, 2017).

Kedua, produksi cengkeh, berdasarkan hasil penelitian yang dilakukan oleh peneliti menunjukkan bahwa faktor perubahan sosial ekonomi masyarakat Kindang Kabupaten Bulukumba, dipengaruhi oleh meningkatnya hasil produktifitas cengkeh pada masa reformasi. Dengan adanya keterbukaan dan kebebasan di era reformasi, mampu mengubah taraf kehidupan masyarakat menjadi lebih baik dan stratifikasi sosial meningkat. Dengan meningkatnya perekonomian masyarakat Kindang yang ditandai dengan berubahnya gaya hidup dan bertambahnya barang-barang kepemilikan masyarakat Kindang seperti motor dan mobil bahkan bangunan rumahnya pun sudah mengikuti gaya bangunan modern, serta banyaknya masyarakat yang telah menunaikan ibadah haji.

Ketiga, faktor geografis, berdasarkan observasi dan penelitian yang dilakukan oleh peneliti menunjukkan bahwa letak geografis Kindang yang berada pada wilayah dataran tinggi dan iklim yang sangat cocok untuk menanam tanaman jangka panjang seperti cengkeh. Tanaman cengkeh merupakan tanaman yang sangat familiar saat ini dengan nilai ekonomis yang tinggi, sehingga dapat mempengaruhi perkembangan perekonomian masyarakat Kindang Kabupaten Bulukumba.

\section{Proses perubahan sosial ekonomi pada masyarakat Kindang Kabupaten Bulukumba.}

Perubahan sosial mencakup tiga gagasan yakni pertama, adanya perbedaan, dalam hal ini suatu keadaan berbeda dengan keadaan lainya yang telah mengalami perubahan. $K e d u a$, terjadi pada waktu yang berbeda, yakni perubahan terjadi bukan dalam satu waktu yang bersamaan namun terjadi dalam waktu yang berbeda dengan jangka waktu tertentu. Ketiga, di antara keadaan sistem sosial yang sama (Sztompka, 1994).

Hal serupa terjadi pada masyarakat Kindang, dimana proses perubahannya terjadi pada keadaan dan waktu yang berbeda. Berdasarkan hasil observasi dan penelitian yang dilakukan oleh peneliti menunjukkan bahwa masyarakat Kindang Kabupaten Bulukumba mengalami peroses perubahan pada peralihan resim Orde Baru ke Reformasi (primitifberkembang- moderen). Pertama, resim Orde Baru, berdasarkan hasil penelitian yang dilakukan oleh peneliti bahwa pada tahun 1980 kondisi sosial ekonomi masyarakat Kindang sangat terpuruk dengan harga jual komoditas cengkeh yang rendah. Umumnya hal tersebut diakibatkan oleh pemerintah orde baru yang memainkan monopoli harga pada komoditas cengkeh.

Upaya pemerintah untuk menanggulangi masalah ketertinggalan dan krisis ekonomi yang melanda masyarakat Kindang dengan mengupayakan rehabilitasi tanaman cengkeh dengan menganjurkan pada masyarakat Kindang untuk mengganti tanaman cengkeh ke komuditi lain yang lebih produktif seperti kopi dan cacao kembali 
dikembangkan. Bahkan dalam upaya rehabilitasi tanaman tersebut pemerintah memberikan biayaa ganti rugi sebesar lima ribu rupiah per pohonnya. Seperti yang dikemukakan oleh (Agustang, 2007), dalam hal menanggulangi ketertinggalan dan krisis ekonomi antara lain menjaga stabilitas makro ekonomi, stabilitas harga, menciptakan lapangan kerja produktif, menjaga iklim investasi, menjaga regulasi perdagangan, meningkatkan produktivitas sektor pertanian, dan mengembangkan infrastruktur wilayah tertinggal.

Kedua, masa reformasi, berdasarkan hasil penelitian yang dilakukan oleh peneliti menunjukkan bahwa Perubahan sosial ekonomi pada masyarakat Kindang terjadi secara signifikan pada masa reformasi. Dimana pada masa reformasi tersebut mengalami kebebasan dan keterbukaan dalam mendistribusikan hasil pertaniannya secara personal. Dengan adanya pendistribusian secara personal ini dapat meningkatkan perekonomian masyarakat Kindang. Naiknya harga komuditas cengkeh yang mencapai 250.000 rupiah perkilonya menjadi salah satu faktor meningkatnya sumber penghasilan masyarakat Kindang saat ini.

\section{Dampak perubahan sosial ekonomi pada masyarakat Kindang Kabupaten Bulukumba.}

Pada pembahasan ini akan dibahas mengenai dampak perubahan sosial ekonomi pada masyarakat Kindang Kabupaten Bulukumba. Berdasarkan hasil penelitian yang dilakukan oleh peneliti menunjukkan bahwa perubahan sosial ekonomi pada masyarakat Kindang sangat mempengaruhi tiga aspek berikut, yakni Pendidikan, politik, dan kebudayaan.

Pertama, pendidikan, mayoritas informan mengakui bahwa meningkatnya kesadaran masyarakat dalam hal pendidikan itu didukung oleh meningkatnya hasil perekonomian masyarakat itu sendiri yang mayoritas petani komuditi cengkeh, bahkan tidak sedikit orang- orang Kindang terutama pada kalangan pemuda yang menempuh pendidikan sampai pada jenjang megister di daerah Jawa, kemudian kembali untuk menjadi seorang pendidik bahkan ada yang menjadi seorang dosen disalah satu universitas.

Pendidikan merupakan usaha yang sengaja secara sadar dan terencana untuk membantu meningkatkan perkembangan potensi dan kemampuan anak agar bermanfaat bagi kepentingan hidupnya sebagai seorang individu dan sebagai warga masyarakat. (Agustang, 2011a) mengungkapkan bahwa pendidikan ialah usaha yang sengaja diadakan, baik langsung maupun tidak langsung, untuk membantu anak untuk mencapai kedewasaan. Orang yakin dan percaya untuk menanggulangi kemiskinan, cara utama adalah dengan memperbesar jumlah penduduk yang bersekolah dan terdidik dengan baik, dapat menjadi kekuatan, baik untuk dominasi maupun untuk emansipasi menurut Giroux (Agustang, 2015). Dengan kata lain, pendidikan dipandang sebagai jalan menuju kemakmuran.

Kedua, bidang politik, berdasarkan hasil penelitian yang dilakukan oleh peneliti menunjukkan bahwa mayoritas informan menyatakan, seiring dengan berkembangnya pendidikan dapat mempengaruhi pola pikir masyarakat Kindang untuk ikut serta mencalonkan diri untuk memperoleh kedudukan dalam sistem pemerintahan. Hal tersebut ditandai dengan adanya beberapa orang Kindang yang mencoba terjun kedunia politik bahkan sudah ada yang menjadi bagian dari struktur lembaga kepemerintahan.

Ketiga, kebudayaan, berdasarkan hasil penelitian yang dilakukan oleh peneliti menunjukkan bahwa masyarakat Kindang mengalami perubahan kebiasaan dalam hal gaya 
hidup. Perubahan mayoritas terlihat pada kaum pemuda, yang hampir tidak terlihat lagi budaya gotong royong pada generasi pemuda saat ini. Hal tersebut dikarenakan pemuda Kindang lebih dominan bergaul di perkotaan sehingga pola pikri dan perilakunya pun mengikuti gaya hidup orang kota yang individualis dan modern.

Hasil penelitian ini relevan dengan penelitian terdahulu yang telah dilakukan oleh (Tahang, n.d.), dimana hasil penelitian tersebut berusaha menemukan bagaimana perubahan sosial yang terjadi pada masyarakat nelayan di Kelurahan Pulau Barrang Lompo Kecamatan Ujung Tanah Kota Makassar, dalam memenuhi berbagai kebutuhan hidup rumah tangganya, ditambah tidak adanya keterlibatan aktif kaum perempuan dalam pemberdayaan ekonomi keluarga atas hasil tangkapan yang diperoleh. Adapun hasil penelitiannya, ketersediaan infrastruktur dermaga, puskesmas, sekolah, jalan raya, dan sarana ibadah merupakan wujud dan peralihan penggunaan teknologi motorisasi menyebabkan perubahan hubungan pola kerja dari bersifat individual menjadi kerja kelompok, terutama pada aspek pembagian dan distribusi hasil tangkap, serta kepemimpinan ekonomi local yang dikuasai oleh para pemilik modal, hal tersebut merupakan proses perubahan sosial ekonomi.

Adapun persamaan penelitian in dengan penelitian terdahulu yakni untuk mengetahui dinamika perubahan sosial ekonomi masyarakat, sedangkan perbedaan yang kemudian muncul dalam penelitian ini jika dikaitkan dengan penelitian terdahulu yaitu penelitian terdahulu lebih merujuk pada upaya memenuhi berbagai kebutuhan hidup dalam rumah tangganya, dan tidak adanya keterlibatan aktif kaum perempuan dalam pemberdayaan ekonomi keluarga. Sedangkan penelitian ini lebih merujuk pada faktor, proses, dan dampak perubahan sosial ekonomi masyarakat Kindang.

Dalam kehidupan masyarakat sangat ditentukan oleh sektor ekonomi yang mempengaruhi berbagai sektor lainnya. Sebagaimana dijelaskan oleh Marx dalam (Ritzer \& Godman, n.d.) bahwa: Determinisme ekonomi dimana sistem ekonomi berperan penting untuk menentukan sektor masyarakat lainnya seperti politik, agama, sistem ide, dan seterusnya. Dengan kata lain masyarakat memiliki dua sektor yakni sektor infrastruktur dan suprastruktur, ekonomi menjadi sector infrastruktur kehidupan dan sektor suprastrukturnya adalah semua sistem-sistem sosial. Asumsi dasarnya ialah jika insfratuktur mengalami perubahan maka semua sistem-sistem sosial atau suprastruktur juga mengalami perubahan. Begitu pula pada masyarakat Kindang Kabupaten Bulukumba, kehidupan masyarakat Kindang ditentukan dan dikendalikan oleh ekonomi, sebagai contoh masyarakat Kindang saat ini melahirkan para tokoh- tokoh masyarakat yang berpotensi, karena dilatar belakang oleh pendidikan yang baik. Hal tersebut dipengaruhi oleh meningkatnya perekonomian masyarakat Kindang sehingga dilirik oleh masyarakat luar.

\section{PENUTUP}

Perubahan sosial ekonomi pada masyarakat Kindang Kabupaten Bulukumba dilandasi oleh berbagai faktor yakni faktor eksternal dan faktor internal. Faktor eksternal meliputi: Faktor pengaruh budaya luar, dan perkembangan teknologi. Sedangkan faktor internal meliputi: Faktor struktural, produksi cengkeh, dan letak geografis. Proses perubahan masyarakat Kindang terjadi pada keadaan dan waktu yang berbeda, yakni 
diantara peralihan resim orde baru ke era reformasi. Dampak dari meningkatnya perekonomian masyarakat Kindang sangat mempengaruhi tingkat Pendidikan, politik, dan budaya. Ditengah- tengah berkembangnya perekonomian masyarakat Kindang, diharapkan kepada para orang tua untuk lebih ketat dalam memberikan pengawasan terhadap anaknya, agar supaya tidak terjerumus pada perilaku yang kurang baik seperti penggunaan obatobatan dan sifat konsumerisme.

\section{DAFTAR PUSTAKA}

Agustang, A. (2007). Entaskan Kemiskinan: Analisis Kinerja Pembangunan Indonesia. Makassar: Indobis Publisher.

Agustang, A. (2011a). Filosofi Research (Dalam Upaya Pengembangan Ilmu). Makassar. Agustang, A. (2011b). Pendekatan Penelitian Kualitatif dan Kuantitatif Suatu Tinjauan Kritis. Makassar: Andira Publisher.

Agustang, A. (2015). Dasar-Dasar Filsafat Penelitian Untuk Pengembangan Ilmu. CV Multi Global, Jalan Maccini Sawah.

Creswell, J. W. (2009). Research Design: Qualitative, Quantitative, and Mixed Methods Approaches. SAGE.

Creswell, J. W., \& Creswell, J. D. (2017). Research design: Qualitative, quantitative, and mixed methods approaches. Sage publications.

Gilarso, T. (2004). Pengantar ilmu ekonomi makro. Kanisius.

Kebung, K. (2017). Membaca 'Kuasa'Michel Foucault dalam Konteks 'Kekuasaan'di Indonesia. MELINTAS, 33(1), 34-51.

Miles, M. B., Huberman, A. M., \& Saldana, J. (2014). Qualitative Data Analysis: A Method Sourcebook. Routledge.

Ritzer, G., \& Godman, J. (n.d.). Douglas. 2010. Teori Sosiologi Modern.

Rohani, R. (2016). Pengaruh Pertumbuhan Penduduk, Pertumbuhan Ekonomi, Pengangguran, dan Inflasi Terhadap Tingkat Kemiskinan di Provinsi Sulawesi Selatan. Universitas Islam Negeri Alauddin Makassar.

Samud, S. (2018). Peranan Pemerintah Dalam Mensejahterakan Masyarakat Melalui Bantuan Sosial Perspektif Ekonomi Islam. Al-Amwal: Jurnal Ekonomi Dan Perbankan Syari'ah, 10(2), 215-228.

Sztompka, P. (1994). The sociology of social change. Blackwell Oxford.

Tahang, H. (n.d.). Analisis Penilaian Manfaat Ekonomi Terumbu Karang Perairan Pulau Barrang Lompo Makassar. 